\title{
Biosorption of Nickel (II) from Aqueous Solution onto Activated Carbon Prepared from Chicken Feather
}

\author{
PAUL, ED; NWOKEM, NC; *ANUMONYE, FU \\ Department of Chemistry, Ahmadu Bello University, Zaria, Nigeria \\ *Corresponding Author Email: francisanumonye@gmail.com
}

\begin{abstract}
Industrial waste water is a potential threat to human health mainly because of the presence of nonbiodegradable, hazardous heavy metals. This research focuses on the use of Activated Carbon from Chicken Feathers (ACCF) in the removal of Ni (II) ions from aqueous solution. Fourier Transform Infrared (FTIR) analysis was carried out on ACCF to reveal the functional groups present which will aid adsorption. The optimization of factors such as initial metal ion concentration, $\mathrm{pH}$, and contact time were investigated at ambient temperature. The optimum $\mathrm{pH}$, initial metal ion concentration and contact time were therefore determined. The experimental data obtained for $\mathrm{Ni}^{2+}$ sorption were treated using pseudo first order and second order kinetic models. The adsorption behavior was found to follow pseudo second order kinetics. This study demonstrates the effectiveness of ACCF in the removal of Ni (II) ion from aqueous solution.
\end{abstract}

DOI: https://dx.doi.org/10.4314/jasem.v23i6.9

Copyright: Copyright (C) 2019 Paul et al. This is an open access article distributed under the Creative Commons Attribution License (CCL), which permits unrestricted use, distribution, and reproduction in any medium, provided the original work is properly cited.

Dates: Received: 27 April 2019; Revised: 22 May 2019; Accepted 11 June 2019

Keywords: adsorption, chicken feather, kinetics.

Ion exchange, chemical precipitation, adsorption, etc are amongst the various methods that exist for the removal of toxic metal ions from aqueous solutions (Sari and Tuzen, 2009). As a result of its capability of removing a wide range of adsorbates, low cost of operation and capability of removing trace level of toxic metals from waste water, adsorption onto activated carbon is by far the most versatile and extensively used process (Vimala and Das, 2009; Nwabanne and Igbokwe, 2008). Heavy metals tend to accumulate in living organisms due to their nonbiodegradable nature, thus causing several diseases and body malfunctions (Gupta and Rastogi, 2009). Biosorption is a process that utilizes biological materials in order to remove heavy metals from solution via adsorption. The mechanism responsible for biosorption may be one or a combination of complexation, coordination, adsorption, ion exchange, chelation, micro precipitation and electrostatic interaction (Wang and Chen, 2006). In the present research work, Activated Carbon from Chicken Feather (ACCF) as biosorbent to remove Ni (II) ion from aqueous solution and kinetics of adsorption were studied.

\section{MATERIALS AND METHODS}

Collection of chicken feathers: Chicken feathers were obtained from several poultry processing facilities across Zaria metropolis in Kaduna state, Nigeria. They were stored in a clean polyethene bag before analysis was carried out.

Preparation of biosorbent (chicken feather): In order to remove some of the materials attached to the feathers, the feathers were washed severally with distilled water and detergent. It was later left in the open air for several days to get rid of odors.

Preparation of activated carbon from chicken feathers: The chicken feathers were first carbonized inside steel cups with a small hole inserted on the lids for venting gases produced during the carbonization process using a muffle furnace set at $400^{\circ} \mathrm{C}$. This temperature was maintained for 1 hour, then left to cool to ambient temperature. The carbonized feathers were then impregnated with $\mathrm{H}_{3} \mathrm{PO}_{4}$ in 1:1 weight ratio and activation was then carried out using a tubular furnace set at $500^{\circ} \mathrm{C}$, which was maintained for an hour.

Reagents: All chemicals, supplied by Merck Company, were of high analytical grade and stock solution of $\mathrm{Ni}$ (II) was prepared by dissolving appropriate amounts of Nickel chloride hexahydrate $\left(\mathrm{NiCl}_{2} \cdot 6 \mathrm{H}_{2} \mathrm{O}\right)$ in deionized water and then the desired concentrations were provided by diluting the stock solution. Stock solutions of nitric acid and $\mathrm{NaOH} 0.1 \mathrm{~N}$ were also prepared. 
Experimental plan: This study investigates some factors such as the initial metal ion concentration (20, $40,60,80$ and $100 \mathrm{mg} / \mathrm{l}), \mathrm{pH}(2,3,5,7,9,11)$ and contact time (10, 20, 30, 45, 60, $120 \mathrm{~min})$ using batch adsorption technique. The nitric acid and $\mathrm{NaOH} 0.1 \mathrm{~N}$ were used to adjust the $\mathrm{pH}$ of the solution (Rakesh and Rosy, 2017). The amount of metal ion adsorbed at equilibrium qe, $(\mathrm{mg} / \mathrm{g})$ was calculated by Equation:

$$
q_{e}=\frac{V\left(C_{i}-C_{f}\right)}{S}
$$

$\mathrm{qe}=$ Metal ion uptake capacity $(\mathrm{mgg}-1), \mathrm{Ci}=$ Initial concentration of metal in solution $(\mathrm{ppm}), \mathrm{C}_{\mathrm{f}}=$ Final concentration of metal in solution $(\mathrm{ppm}), \mathrm{S}=$ weight of biosorbent $(\mathrm{g})$, and $\mathrm{V}=$ Solution volume $\left(\mathrm{cm}^{3}\right)$.

The difference between the initial metal ion concentration and final metal ion concentration was assumed to be bound to the biosorbent.

The Biosorption efficiency, A \%, of the metal ion was calculated from:

$$
\mathrm{A} \%=\frac{\mathrm{C}_{\mathrm{o}}-\mathrm{C}_{\mathrm{e}}}{\mathrm{C}_{\mathrm{o}}} \times 100
$$

Where $\mathrm{C}_{0}$ and $\mathrm{Ce}$ are the initial and equilibrium metal ion concentrations (ppm), respectively (Ding et al., 2012).

\section{RESULTS AND DISCUSSION}

Characteristics of the Activated Carbon: Fourier transform infrared (FTIR) spectroscopy was used to measure the carbons of the adsorbent within the range of $400-4000 \mathrm{~cm}^{-1}$ wave number. The FTIR technique was an important tool to identify functional groups, which are capable of adsorbing heavy metal ions. The FTIR spectrum of ACCF showed that the most prominent peaks in the spectrum originate from $\mathrm{H}-\mathrm{C}$ $\mathrm{H}$ asymmetric and symmetric stretching vibrations from alkanes ( 2924.18 to $\left.2854.74 \mathrm{~cm}^{-1}\right)$. At (1635.69 $\mathrm{cm}^{-1}$ ) is a stretching mode of carbonyls mainly ketones of $\mathrm{C}=\mathrm{O}$. Intense peaks in region (1512.24 to 1411.94 $\mathrm{cm}^{-1}$ ) originate from the secondary Amines N-H, while stretching at $\left(1157.33 \mathrm{~cm}^{-1}\right)$ for $\mathrm{C}-\mathrm{O}$ come from ethers. Peaks observed at $\left(2360.95 \mathrm{~cm}^{-1}\right)$ originated from $\mathrm{C} \equiv \mathrm{C}$ or $\mathrm{C} \equiv \mathrm{N}$.

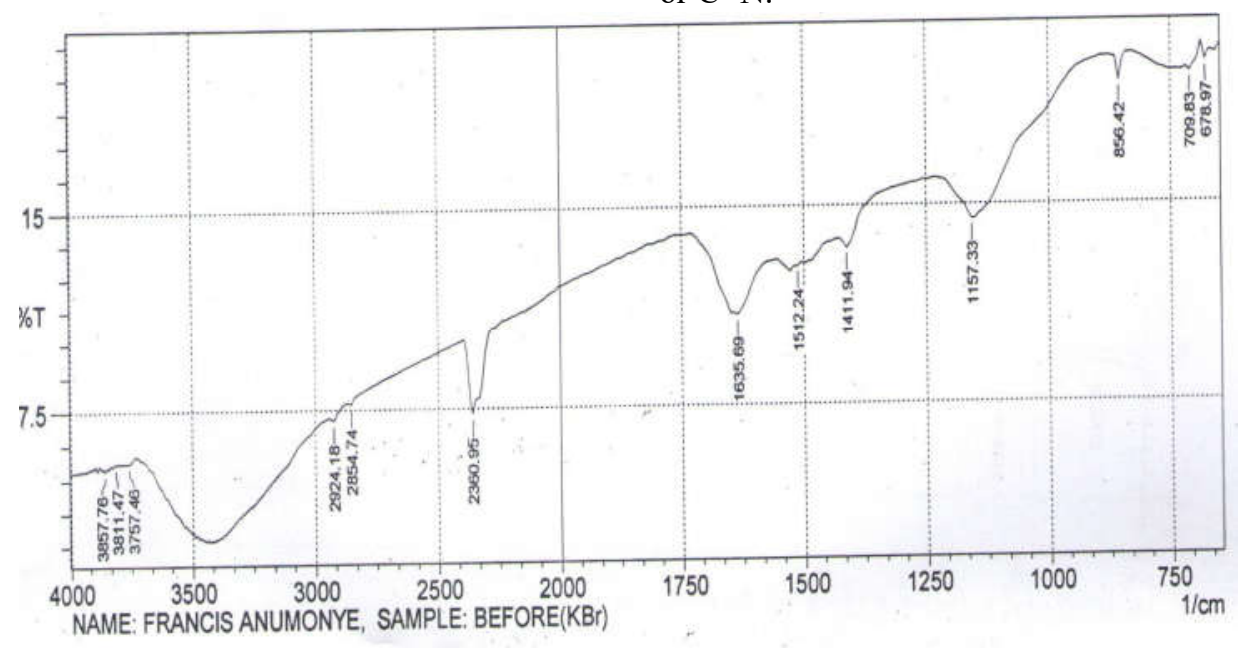

Fig.1. Fourier Transform Infrared Spectroscopy (FTIR) of ACCF

Effect of Initial Concentration: Results from figure 2 showed that the removal efficiencies of $\mathrm{Ni}$ (II) by ACCF decreased as the initial concentration was increased from $20 \mathrm{mg} / \mathrm{L}$ to $100 \mathrm{mg} / \mathrm{L}$. This is because for a fixed dose of the biomass the total available binding sites are limited, thus an increase in initial concentration from $20 \mathrm{mg} / \mathrm{L}$ resulted in the exhaustion of the available binding site on the biosorbent. These results are consistent with the results obtained by Namasivayam et al., 1996. The maximum Ni (II) ion removal occurred at initial concentration of $20 \mathrm{mg} / \mathrm{L}$ with percentage sorption of $96.715 \%$.

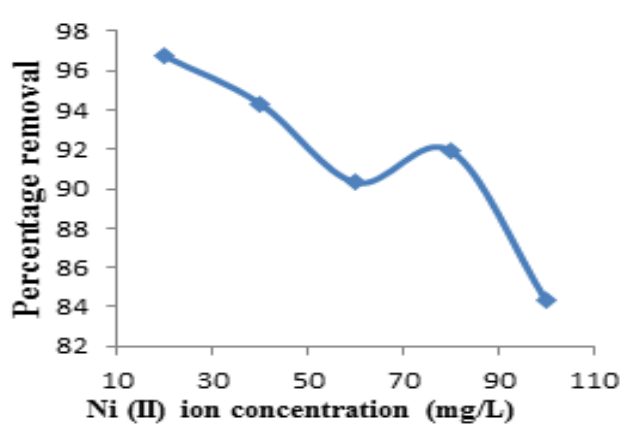

Fig.2. Effect of Initial concentration on the Removal of Ni (II) using ACCF 
Effect of $p H$ : The $\mathrm{pH}$ level of the aqueous solution is an important variable for the adsorption of metals on the adsorbent. The effect of $\mathrm{pH}$ on the removal of nickel ion using ACCF as an adsorbent was studied with initial $\mathrm{pH}$ range from 2 - 11 . The relation between the initial $\mathrm{pH}$ of the solution and percentage removal of nickel ion is depicted in table 1. It was observed that maximum percentage sorption of nickel ions occurred at $\mathrm{pH} 9$ with corresponding percentage removal of $95.99 \%$. With increasing $\mathrm{pH}$, electrostatic repulsion decreases due to reduction of positive charge density of proton on the sorption sites thus resulting in enhanced metal adsorption. Similar observations were reported by earlier researchers (Momcilović et al., 2011).

Table.1. Effect of $\mathrm{pH}$ on the Removal of Ni (II) using ACCF

\begin{tabular}{ll}
\hline $\mathbf{p H}$ & Percentage removal of Nickel $(\%)$ \\
\hline 2 & 93.565 \\
3 & 95.175 \\
5 & 94.645 \\
7 & 94.525 \\
9 & 95.99 \\
11 & 95.98 \\
\hline
\end{tabular}

Effect of Contact time: Effect of contact time on $\mathrm{Ni}$ (II) removal by the sorbent is illustrated in figure 3. Rapid metal uptake in first 30 minutes was due to availability of binding sites within the sorbent, since adsorption kinetics depends on the sorbent surface area (Qader and Akhtar, 2005). Once the available binding sites were used up and clogged by metal ions, the metal uptake rate was decreased. The highest removal $(99.285 \%)$ was attained by ACCF at 60 minutes. After the adsorption equilibrium had reached on 60 minutes, a decrease in the metal uptake was observed on 120 minutes. Therefore optimum contact time for this kind of biosorbent is 60 minutes.

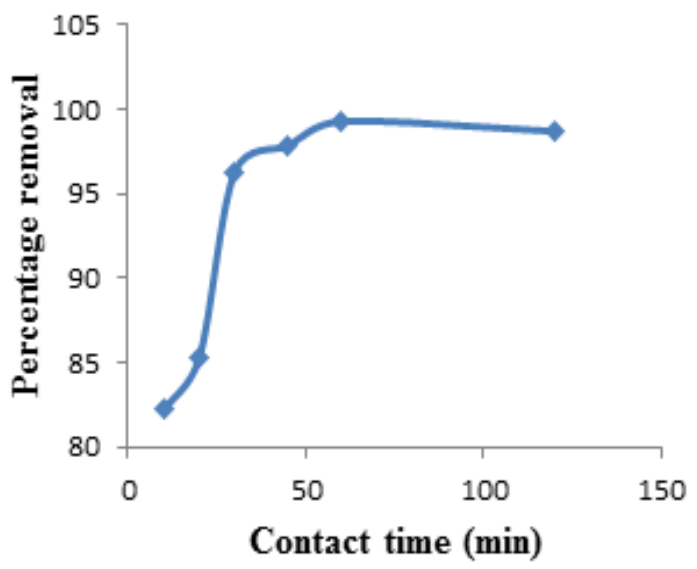

Fig.3. Effect of Contact time on the Removal of Ni (II) using ACCF
Adsorption kinetics: Adsorption kinetics was used to explain the adsorption mechanism and characteristics. Pseudo-first order and pseudo-second order kinetic models were applied to experimental data in order to investigate the kinetics of sorption of heavy metal ions onto ACCF. Kinetic study was conducted in optimum conditions determined in the preliminary experiments (initial concentration - $20 \mathrm{mg} / \mathrm{dm} 3$, temperature - 298 $\mathrm{K}$ and $\mathrm{pH}-9)$.

Pseudo first order model: Pseudo first order equation or Lagergren kinetics equation (Lagergren, 1898) is widely used for the adsorption of an adsorbate from an aqueous solution and given in linearized form as presented in equation (1).

$\log \left(q_{e}-q_{t}\right)=\log q_{e}-\frac{k_{1}}{2.303} t$

Where $\mathrm{q}_{\mathrm{t}}\left(\mathrm{mg} \mathrm{g}^{-1}\right)$ is the amount of $\mathrm{Ni}$ (II) adsorbed per unit mass of adsorbent at time $\mathrm{t}, \mathrm{K}_{1}\left(\mathrm{~L} \mathrm{~min}{ }^{-1}\right)$ is the Pseudo first order rate constant, $\mathrm{t}$ ( $\mathrm{min}$ ) is the time taken and $\mathrm{q}_{\mathrm{e}}\left(\mathrm{mg} \mathrm{g}^{-1}\right)$ is the amount of $\mathrm{Ni}$ (II) adsorbed per unit mass of adsorbent at equilibrium. A correlation coefficient, $\mathrm{R}^{2}$ value close to 1 indicates an inclination towards physisorption.

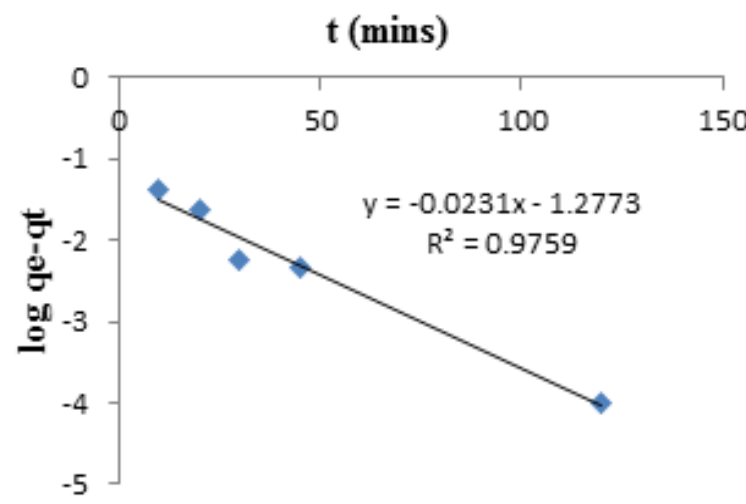

Fig.4. Pseudo first order model for Ni (II) removal using ACCF

Correlation coefficient, $\mathrm{R}^{2}(0.9759)$ value indicates that the data fits into Pseudo first order kinetics model.

Pseudo second order model: Ho and McKay, 1991 suggested the Pseudo second order kinetic as presented in equation (2)

$\frac{\mathrm{t}}{\mathrm{q}_{\mathrm{t}}}=\frac{1}{\mathrm{k}_{2} \mathrm{q}_{\mathrm{e}}^{2}}+\frac{\mathrm{t}}{\mathrm{q}_{\mathrm{e}}}$

Where $\mathrm{K}_{2}$ is the pseudo first order rate constant ( $\mathrm{g} \mathrm{mg}^{-}$ $\left.{ }^{1} . \mathrm{min}\right), \mathrm{q}_{\mathrm{e}}\left(\mathrm{mg} \mathrm{g}^{-1}\right)$ is the amount of $\mathrm{Ni}$ (II) adsorbed per unit mass of adsorbent and $\mathrm{q}_{t}$ is the amount of $\mathrm{Ni}$ (II) adsorbed per unit mass of adsorbent at time t. A correlation coefficient, $\mathrm{R}^{2}$ value close to 1 indicates an inclination towards chemisorption. 


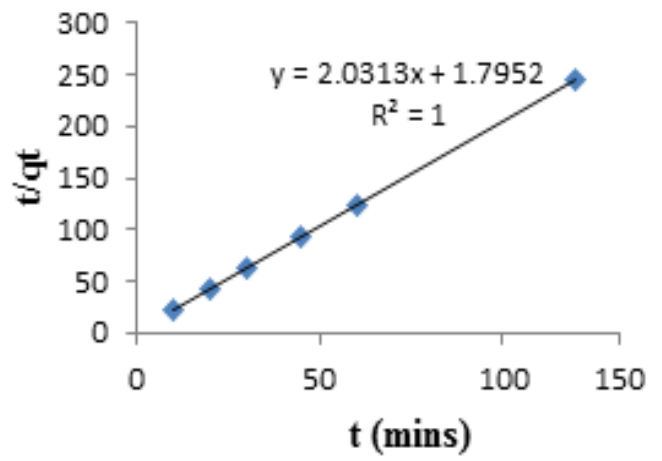

Fig.5. Pseudo second order model for Ni (II) removal using ACCF

Correlation coefficient, $R^{2}(1)$ value suggests that the data fits into Pseudo second order kinetics model thus indicating that adsorption process occurred via chemisorption.

Conclusion: This study showed that ACCF could be used as an effective and efficient biosorbent for the removal of $\mathrm{Ni}$ (II) ions from aqueous solution. The biosorption process was affected by contact time, $\mathrm{pH}$ and initial concentration. Adsorption kinetics was found to follow both first and second-order rate expressions. However, the experimental data showed better fit with pseudo-second order model with higher correlation coefficients. The use of ACCF as an adsorbent clearly seems to be an economical and promising alternative over conventional methods.

\section{REFERENCE}

Gupta, VK; Rastogi, A (2009). Biosorption of hexavalent chromium by raw and acid-treated green alga Oedogonium hatei from aqueous solutions. J. Hazard. Mater. 163: 396-402.

Lagergren, S (1898). About the theory of so-called adsorption of soluble substances. Kungliga svenska ventenskapsatemiens. Handlinger, 24:139.

Momčilović, M; Purenović, M; Bojić, A; Zarubica, A; Ranđelović, M (2011). Removal of lead (II) ions from aqueous solutions by adsorption onto pine cone activated carbon. Desalination, 2011, 27: 653-59.

Namasivayam, C; Muniasamy, N; Gayathri, M; Rani, M; Renganathan, K (1996). Removal of dyes from aqueous solution by cellulosic waste orange peel, Biores. Techno. 57, 3 - 43.

Nwabanne, JT; Igbokwe, PK (2008). Kinetics and equilibrium modeling of nickel adsorption by cassava peel. J. Eng. Appl. Sci. (JEAS), 3, 829

Qadeer, R; Akhtar, S (2005). Kinetics study of lead ion adsorption on active carbon. Turk. J. Chem. 29, pp.95-99.

Rakesh, KE; Rosy, A; (2017). Bio sorption Studies of Chromium Ions with Modified Chicken Feathers Biomed J Sci \& Tech Res 1(7).

Sari, A; Tuzen, M (2009). Kinetic and equilibrium studies of biosorption of $\mathrm{Pb}(\mathrm{II})$ and $\mathrm{Cd}(\mathrm{II})$ from aqueous solution by macrofungus (Amanita rubescens) biomass. J. Hazard. Mater. 164:10041011.

Vimala, R; Das, SN (2009). Biosorption of cadmium (II) and lead (II) from aqueous solutions by using mushrooms: a comparative study. J. Hazard. Matter, 168: 376-382.

Wang, JL; Chen, C (2006). Biosorption of heavy metals by Saccharomyces cerevisiae: a review. Biotechnol Adv; 24:427-51. 